\title{
In-silico analysis of mt-C01 gene of Taenia hydatigena sheep isolates
}

\author{
F. CELIK' ${ }^{1}$, S. GUNYAKTi KILINC ${ }^{1,2}$, H. KAYA KESIK², H. AHMED ${ }^{3}$, S. SIMSEK ${ }^{1, *}$ \\ 1'Department of Parasitology, Faculty of Veterinary Medicine, University of Firat, 23119, Elazig, Turkey, \\ *E-mail: ssimsek@firat.edu.tr, ${ }^{2}$ Department of Parasitology, Faculty of Veterinary Medicine, University of Bingöl, Bingöl, Turkey; \\ ${ }^{3}$ Department of Biosciences, COMSATS University Islamabad (CUI), Park Road, Chakh Shahzad, Islamabad, Pakistan
}

Article info

Received April 22, 2020

Accepted October 9, 2020

\section{Summary}

Taenia hydatigena is a tapeworm that affects herbivores in different regions of the world. Cysticercus tenuicollis (larvae of T. hydatigena), is prevalent in ruminants and pigs. In the current study, phylogenetic analysis of the published mt-CO1 gene of $C$. tenuicollis sheep isolates was analyzed using in-silico method and vertical and horizontal transmission at the global level by using a meta-analysis approach. A total of $82 \mathrm{mt}-\mathrm{CO} 1$ nucleotide sequences (339 bp) of $C$. tenuicollis sheep isolates from the NCBI database (Italy -Sardinia-, Iran, Palestine, Iraq, Finland, India and China) were used to investigate haplotype and genetic relationships. Tajima's D $(-2,2984)$ value was negative for the $\mathrm{mt}-\mathrm{CO} 1$ sequences signifying the population expansion and/or purifying selection. The highly negative Fu's Fs $(-60,528)$ values determined for the sequences reflecting the existence of uncommon haplotypes. The mt-CO1 of $\mathrm{C}$. tenuicollis haplotype network had 47 haplotypes arranged within a star-like configuration with a main haplotype, which encompassed $25.6 \%$ of the total isolates. In the mt-C01 haplotype network analyzed, there were $80.5 \%$ unique single haplotype and highest ratio was observed in C. tenuicollis from sheep originating from Iran, followed by Sardinia, Palestine and Finland. If the current condition continues, genetic differences in $T$. hydatigena will be able to rise, and possible new strains and/or genotypes that may influence the host adaptation and life cycle of the parasite may emerge.

Keywords: Taenia hydatigena; Cysticercus tenuicollis; sheep; C01; in-silico analysis

\section{Introduction}

Taenia hydatigena is a cosmopolitan cestode parasite and adults reside in the small intestine of dogs and the other carnivores (such as foxes, jackals, wolves and hyenas). Cysticercus tenuicollis, which is the metacestode, lives mainly on sheep, goats, cattle, pigs, deer and horses as well (Taylor et al., 2007). The eggs released from the gravid proglottids are passed out with the feaces of the final host resulting spread the infection after being injected by the intermediate hosts during grazing. Large pasture areas, infected shepherd and stray dogs and illegal slaughtering are important factors in the spread of $C$. tenuicollis (Harandi et al., 2011; Varcasia et al., 2011). The oncospheres, which are released from the eggs taken, first migrates to the liver, and then some of it adheres to the liver, but most of them come to the surface of the omentum and mesentery. However, there are few studies reporting that $\mathrm{C}$. tenuicollis is rarely localized in the lungs, kidneys, brain, ovaries, uterus, cervix and vagina (Utuk \& Piskin, 2012; Scala et al., 2015). Cysticercus tenuicollis consists of a thin-walled cyst filled with a serous fluid and an invaginated scolex (Chemben-

\footnotetext{
$\bar{*}$ - corresponding author
} 
sofu et al., 2017). The majority of diseases are asymptomatic and usually do not attract attention to the slaughtered animals. Clinical findings vary according to the severity of the infection (Chembensofu et al., 2017). There is some evidence that cysticercus larvae, especially those located in the liver, are as harmful as in the peritoneal cavity (Kaufmann, 2013). It has been reported that larvae migrating in severe infections, especially in young animals, can cause eosinophilia in the liver parenchyma and severe destruction of the liver parenchyma with heavy inflammation, which can sometimes be fatal. In addition to creating an animal health problem, cysticercosis is important in terms of causing economic losses for the meat industry (Scala et al., 2016). In Italy, economic losses due to cysticercosis were $0.40 €$ per kilogram, 315,622.2 €/year in liver destruction, 18,035.5 €/year in offal, and approximately $333,657 €$ in total (Scala et al., 2015).

The prevalence and economic importance of $C$. tenuicollis were reported in some European countries (Scala et al., 2015). The prevalence of $C$. tenuicollis in sheep was $15.17 \%$ in India (Nimbalkar et al., 2011), 0.2 \% in Tanzania (Mellau et al., 2010), $16.93 \%$ in Egypt (Sultan et al., 2010), $13.03 \%$ in Nigeria (Saulawa et al., 2011), 79 \% in Ethiopia (Sissay et al., 2008) and $12.87 \%$ in Iran (Rostami et al., 2015). In Turkey, the prevalence rate of $C$. tenuicollis in sheep ranged between $12.3 \%$ and $65.67 \%$ (Deger et al., 2001; Aydin, 2003; Deger \& Bicek, 2005; Kara et al., 2009; Adwan et al., 2018).

For the molecular characterization of T. hydatigena isolates, mostly mitochondrial cytochrome $c$ oxidase 1 (CO1) gene has been preferred. It is due to the mt-C01 gene can better and more reliably identify the genetic relationship among the isolates (Boufana et al., 2015a, b).

This study aimed to evaluate the phylogenetic analysis of $T$. hydatigena's sheep isolates (C. tenuicollis) by in-silico method using the mt-C01 gene sequences reterived from National Center for Biotechnology Information, USA, (NCBI) (www.ncbi.nlm.nih.gov).

\section{Materials and Methods}

\section{Data Collection}

In current study, the mt-C01 gene sequences of $T$. hydatigena's sheep isolates which were submitted to The National Center for Biotechnology Information, USA, (NCBI) (www.ncbi.nlm.nih.gov) until October $24^{\text {th }}, 2019$ were retrieved and dataset were created. As a result of the sequence data search in NCBI database, a total of 86 sequence data was obtained.

\section{Data and Phylogenetic Analysis}

The mt-C01 sequences were individually downloaded in FASTA format from NCBI database and uploaded to the MEGAX program (Kumar et al., 2018). By aligning of the different length sequences, a consensus reference sequence (accession number GQ228819) of $T$. hydatigena was selected. All sequences were aligned to the consensus sequence, then $339 \mathrm{bp}$ length sequences were selected, which did not have indel problems. A total of 82 sequences selected by this strategy and were trimmed at both ends and the length of the sequences were equalized. Later on, these sequences were analyzed in the MEGAX program by the Akaike Information Criterion (AIC) and The Bayesian Information Criterion, and the most suitable base change models were obtained. Following, the phylogenetic tree was constructed by using the Maximum Likelihood (ML) method was obtained with the Hasegawa-Kishino-Yano model. A discrete Gamma distribution was used to model evolutionary rate differences among sites ( 5 categories $(+G$, parameter $=0.1727)$ ). Statistical support for specific clades was obtained via 1000 bootstrap replicates. Evolutionary analyses were conducted in MEGA X (Kumar et al., 2018).

\section{Haplotype Analysis}

All the sequence data was uploaded on DnaSP 6 (Rozas et al., 2017). The population diversity indices (numbers of haplotype

Table 1. Access numbers of the mt-CO1 gene region of $C$. tenuicollis isolates used in the study.

\begin{tabular}{|c|c|c|c|}
\hline Geographical region & Number of isolates & Accession Numbers & $\begin{array}{l}\text { Genbank } \\
\text { Submit Date }\end{array}$ \\
\hline China & 2 & NC012896 and GQ228819 & 2010 and 2016 \\
\hline Iran & 40 & $\begin{array}{l}J Q 710588 \text { - JQ710599 } \\
\text { JQ710600 - JQ710627 }\end{array}$ & 2012 \\
\hline Palestine & 20 & $\begin{array}{l}\text { KM032284 - KM032299 } \\
\text { KM032300 - KM032303 }\end{array}$ & 2014 \\
\hline Italy (Sardinia) & 14 & $\begin{array}{l}\text { KT372517 - КT372518 } \\
\text { КT372520 - КT372531 }\end{array}$ & 2015 \\
\hline Finland & 1 & EU544551 & 2016 \\
\hline India & 1 & DQ995656 & 2016 \\
\hline Iraq & 4 & MH113919 - MH113922 & 2018 \\
\hline Total & 82 & & \\
\hline
\end{tabular}


Table 2. Diversity and neutrality indices for Taenia hydatigena isolates from sheep originating from various geographical regions using nucleotide data of $\mathrm{mt}-\mathrm{CO} 1(339 \mathrm{bp})$.

\begin{tabular}{lcccccccc}
\hline $\begin{array}{l}\text { Geographical } \\
\text { region }(\mathbf{n})\end{array}$ & $\begin{array}{c}\text { Polymorphic } \\
\text { sites }\end{array}$ & $\boldsymbol{h n}$ & $\boldsymbol{h d} \pm$ SD & $\boldsymbol{n d} \pm \mathbf{S D}$ & Tajima's $\boldsymbol{p}$ & $\boldsymbol{p}$ value & Fu's Fs & $\boldsymbol{p}$ value \\
\hline Palestine (20) & 10 & 9 & $0.705 \pm 0.111$ & $0.004 \pm 0.0011$ & -1.610 & $0.093^{*}$ & -4.546 & 0.008 \\
Iran (40) & 36 & 35 & $0.992 \pm 0.008$ & $0.011 \pm 0.001$ & -2.017 & $0.031^{*}$ & -44.411 & 0.000 \\
Sardinia (14) & 12 & 10 & $0.934 \pm 0.051$ & $0.007 \pm 0.0013$ & -1.501 & $0.125^{*}$ & -5.775 & 0.003 \\
\hline
\end{tabular}

$N$ : number of isolates, $h n$ : number of haplotypes; $h d$ : haplotype diversity; $\pi \mathrm{d}$ : nucleotide diversity; SD: standard deviation

(h), haplotype $(\mathrm{Hd})$ and nucleotide diversities $(\pi))$, the neutrality indices (Tajima's D (Tajima, 1989), and Fu's statistics (Fu, 1997)) were calculated using DnaSP 6 (Rozas et al., 2017). DnaSP 6 was used to generate using a series of output formats, such as NEXUS, which allows the user to add additional information for the next analysis. Geographical, phenotypic or other traits associated with sequences were also be included in NEXUS (Maddison et al., 1997) files in a Traits block. Following networks were created using the minimum spanning networks (MSN) method, which includes all the edges visible in the minimum span tree of arrays by means of PopART-1.7 software (Bandelt et al., 1999) (http:/l popart.otago.ac.nz).

\section{Ethical Approval and/or Informed Consent}

In the current study no informed consent was required from the open resources of gene sequences.

\section{Results}

In this study, a data set of mt-CO1 sequences of $\mathrm{C}$. tenuicollis sheep isolates from NCBI database was used for bioinformatic analysis (Table 1).

Cysticercus tenuicollis populations: for geographical regions diversity and neutrality indices

The diversity and neutrality indices for mt-C01 sequences of $\mathrm{C}$. tenuicollis sheep isolates from Italy (Sardinian), Iran and Palestine are shown in Table 2. Cysticercus tenuicollis in Iranian sheep showed the highest haplotype diversity within the sheep isolates. Tajima's D and Fu's Fs were significantly negative for nearly all the T. hydatigena isolates in the localities. Fu's Fs for Iranian isolates was at least 11 and 8 fold that seen in Palestinian and Sardini- an isolates, respectively, which is a reflection of the presence of unique singleton haplotype characteristics of the Iranian isolates of C. tenuicollis. In addition, the identification of 35 haplotypes in 40 isolates of Iranian origin supports this finding. When the haplotype analysis was done between Iran, Palestine and Italy (Sardinia) isolates; 36 polymorphic regions containing $44.4 \%$ (16/36) parsimony informative sites were detected for $\mathrm{mt}-\mathrm{CO} 1$ sequences in Iranian isolates. The mt-CO1 network consisted of 35 haplotypes, out of them $88.6 \%(31 / 35)$ were geographically unique haplotypes. Although it is not a central main haplotype, the haplotype network that combines 3 nucleotide sequences that make up a maximum of $7.5 \%(3 / 40)$ has been identified. Apart from that, it was observed with $1-11$ mutation points separated from other haplotypes. In Palestinian isolates; 10 polymorphic regions containing $30 \%(3 / 10)$ parsimony informative sites were determined for mt-CO1 sequences. It has been observed that $77.8 \%(7 / 9)$ of the data network consists of 9 geographically unique haplotypes and $55 \%(11 / 20)$ of total isolates are located in a main haplotype point. In Italy (Sardinia) isolates, for the mt-CO1 sequences, 12 polymorphic regions containing $25 \%$ (3/12) parsimony informative sites were identified. $80 \%(8 / 10)$ of the haplotypes consisted of 10 geographically unique haplotypes. The existence of two main haplotypes was determined at the main haplotype point, and it was observed that $21.4 \%(3 / 14)$ of the total isolates were in this main haplotype network.

Cysticercus tenuicollis populations: for geographical regions diversity and neutrality indices

A total of $82 \mathrm{mt}-\mathrm{CO} 1$ nucleotide sequences (339 bp) of C. tenuicollis sheep isolates from the NCBI database from Italy (Sardinia), Iran, Palestine, Iraq, Finland, India and China were used to determine haplotype and genetic relationships. In total, we identified 44 polymorphic sites for mt-C01 sequences, out of which

Table 3. Diversity and neutrality indices for Cysticercus tenuicollis isolates from Sardinia, Iran, Palestine, Iraq, Finland, India and China using nucleotide data of mt-C01 gene (339 bp).

\begin{tabular}{lcccccccc}
\hline $\begin{array}{l}\text { No of } \\
\text { isolates }(\mathrm{n})\end{array}$ & $\begin{array}{c}\text { Polymorphic } \\
\text { sites }\end{array}$ & $h n$ & $h \mathrm{~d} \pm \mathrm{SD}$ & $\pi \mathrm{d} \pm \mathrm{SD}$ & Tajima's $D$ & $p$ value & Fu's Fs & $p$ value \\
\hline Total $(82)$ & 44 & 47 & $0.926 \pm 0.023$ & $0.008 \pm 0.0009$ & -2.2984 & $0.009^{*}$ & -60.528 & 0.000 \\
\hline
\end{tabular}

$n$ : Number of isolates, $h n$ : number of haplotypes; $h d$ : haplotype diversity; $\pi d$ : nucleotide diversity; SD: standard deviation 
Table 4. Grouping haplotypes of Cysticercus tenuicollis mt-CO1 sequences and accession numbers of isolates forming groups.

\begin{tabular}{|c|c|c|}
\hline Haplotype name & No of isolates & Accession Numbers \\
\hline Hap01 & 21 & $\begin{array}{l}\text { KM032303-Palestine, KM032302-Palestine, KM032300-Palestine, } \\
\text { KM032299-Palestine, KM032298-Palestine, KM032289-Palestine, } \\
\text { KM032288-Palestine, KM032287-Palestine, KM032286-Palestine, } \\
\text { KM032285-Palestine, KM032284-Palestine, JQ710614-Iran, JQ710599- } \\
\text { Iran, JQ710588-Iran, KT372530-Italy, KT372529-Italy, KT372522-Italy, } \\
\text { MH113922-Iraq, MH113921-Iraq, MH113920-Iraq, MH113919-Iraq }\end{array}$ \\
\hline Нар02 & 2 & JQ710627-Iran, JQ710594-Iran \\
\hline Нар03 & 1 & JQ710626-Iran \\
\hline Hap04 & 1 & JQ710625-Iran \\
\hline Нар05 & 1 & JQ710624-Iran \\
\hline Нар06 & 1 & JQ710623-Iran \\
\hline Нар07 & 1 & JQ710622-Iran \\
\hline Нар08 & 1 & JQ710621-Iran \\
\hline Hap09 & 1 & JQ710620-Iran \\
\hline Hap10 & 1 & JQ710619-Iran \\
\hline Hap11 & 1 & JQ710618-Iran \\
\hline Hap12 & 2 & JQ710617-Iran, KM032294-Palestine \\
\hline Hap13 & 1 & JQ710616-Iran \\
\hline Hap14 & 1 & JQ710615-Iran \\
\hline Hap15 & 1 & JQ710613-Iran \\
\hline Hap16 & 8 & $\begin{array}{l}\text { JQ710612-Iran, JQ710593-Iran, KT372528-Italy, KT372525-Italy, KT372524- } \\
\text { Italy, KM032292-Palestine, KM032291-Palestine, DQ995656-India }\end{array}$ \\
\hline Hap17 & 1 & JQ710611-Iran \\
\hline Hap18 & 1 & JQ710610-Iran \\
\hline Hap19 & 1 & JQ710609-Iran \\
\hline Нар20 & 1 & JQ710608-Iran \\
\hline Hар21 & 1 & JQ710607-Iran \\
\hline Hap22 & 1 & JQ710606-Iran \\
\hline Hap23 & 1 & JQ710605-Iran \\
\hline Hap24 & 2 & JQ710604-Iran, KM032296-Palestine \\
\hline Hар25 & 1 & JQ710603-Iran \\
\hline Нар26 & 1 & JQ710602-Iran \\
\hline Hap27 & 1 & JQ710601-Iran \\
\hline Hap28 & 2 & JQ710600-Iran, JQ710591-Iran \\
\hline Hар29 & 1 & JQ710598-Iran \\
\hline Нар30 & 1 & JQ710597-Iran \\
\hline Нар31 & 1 & JQ710596-Iran \\
\hline Hар32 & 1 & JQ710595-Iran \\
\hline Нар33 & 2 & JQ710592-Iran, KT372520-Italy \\
\hline Нар34 & 1 & JQ710590-Iran \\
\hline Нар35 & 3 & JQ710589-Iran, KT372518-Italy, KM032301-Palestine \\
\hline Нар36 & 1 & KT372531-Italy \\
\hline
\end{tabular}




\begin{tabular}{lll} 
Hap37 & 1 & KT372527-Italy \\
Hap38 & 1 & KT372526-Italy \\
Hap39 & 1 & KT372523-Italy \\
Hap40 & 1 & KT372521-Italy \\
Hap41 & 1 & KT372517-Italy \\
Hap42 & 1 & KM032297-Palestine \\
Hap43 & 1 & KM032295-Palestine \\
Hap44 & 1 & KM032293-Palestine \\
Hap45 & 1 & KM032290-Palestine \\
Hap46 & 1 & EU544551-Finland \\
Hap47 & 2 & NC012896-China, GQ228819-China \\
\hline
\end{tabular}

$40.9 \%$ (18/44) were parsimony informative. Large haplotype and weak nucleotide diversities were detected in mt-C01 as shown in the Table 3. There were no conserved DNA regions in accordance with the studied sequences. Tajima's D was negative for the mt-C01 partial sequences signifying population expansion and/or purifying selection. The highly negative Fu's Fs values detected for the sequences indicated the presence of unusual haplotypes expected from a recent population enlargement. The existence of unmatched single haplotypes for the mt-CO1 (38/47) sequences of $\mathrm{C}$. tenuicollis was coherent with the structure of the haplotype networks.

\section{Haplotype Networks}

The mt-CO1 of $C$. tenuicollis haplotype network had 47 haplotypes arranged within a star-like configuration with a main haplotype, separated from other haplotypes by $1-11$ mutational steps and which encompassed $25.6 \%$ (Hap01: 21/82) of the total isolates (Table 4).

This principle haplotype contained $55 \%$ (11/20) of the Palestine isolates, $100 \%(4 / 4)$ of the Iraq isolates, $7.5 \%$ (3/40) of the Iran isolates, $21.4 \%(3 / 14)$ of the Italians (Sardinia) isolates of sheep. Again, the second main haplotype was found to represent $9.7 \%$

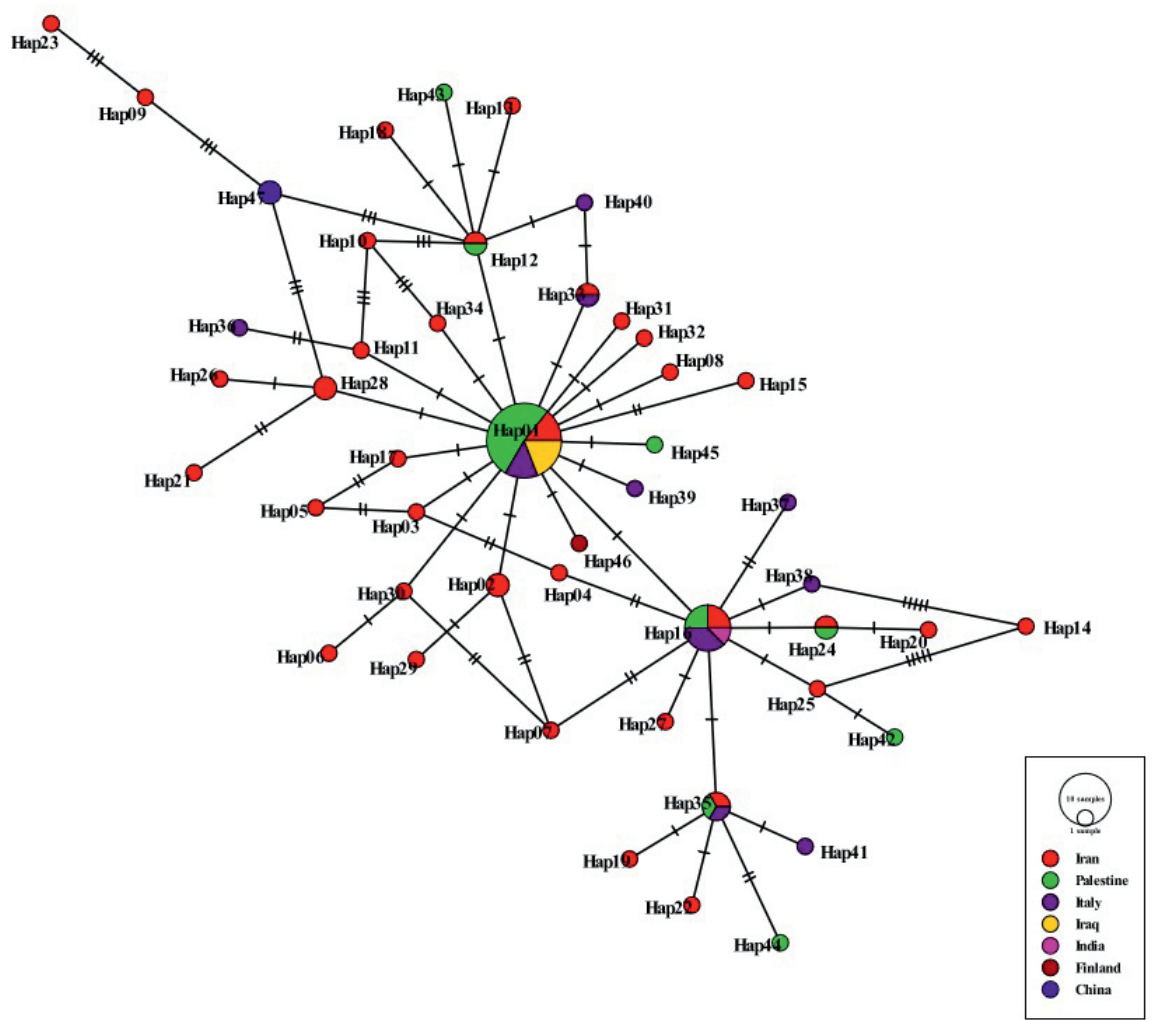

Fig. 1. The appearance of mt-CO1 (339 bp) haplotypes of sheep isolates of Cysticercus tenuicollis. Geographical distribution of the haplotypes is indicated by different colors. The size of the circles is related to the haplotype frequency. Number of mutations distinguishing the haplotypes is shown by hatch marks. 


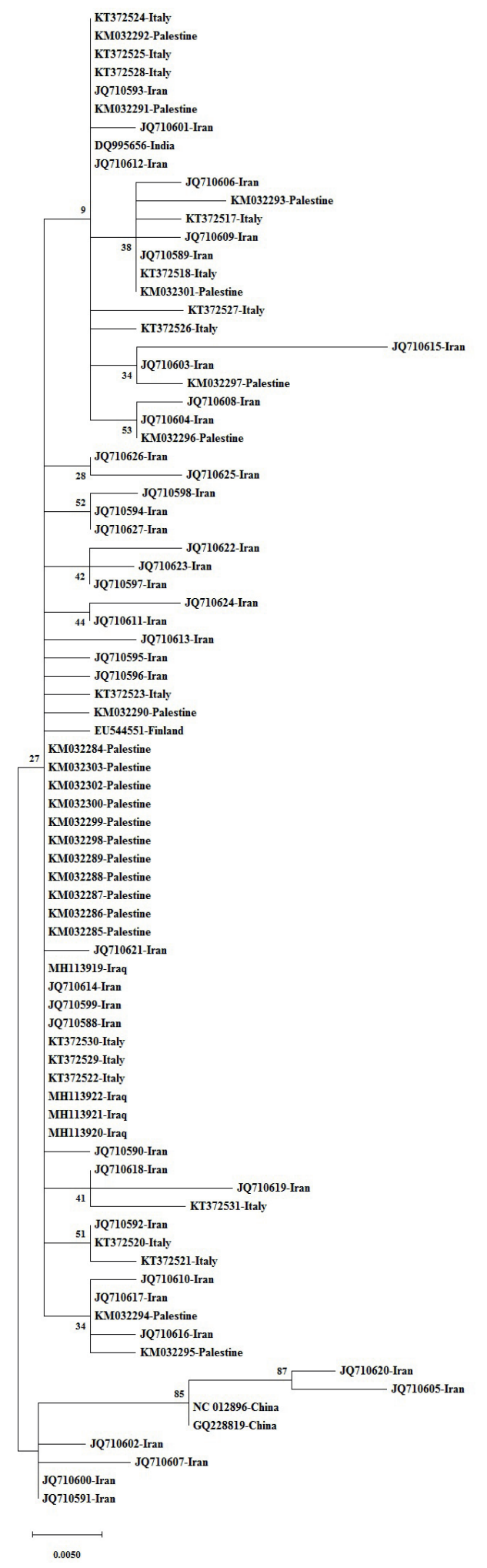

Fig. 2. Phylogenetic tree view of sheep isolates using mt-C01 gene (339 bp) sequences and reference sequences. MEGAX was used to construct a Maximum Likelihood tree based on the HKY $+\mathrm{G}$ model. The reliability of the tree was assessed by 1000 bootstrap replications.
(Hap16: 8/82) of the total isolates. This haplotype placed $100 \%$ (1/1) of India, $21.4 \%$ (3/14) of Italy (Sardinia), $10 \%$ (2/20) of Palestine and $5 \%(2 / 40)$ of Iran isolates. In the mt-CO1 haplotype network analyzed in the study, there were $80.5 \%$ (38/47) unique single haplotype and this ratio was highest observed for $\mathrm{C}$. tenuicollis from sheep originating from Iran $(n=27)$ isolates, followed by Sardinia $(n=6)$, Palestine $(n=4)$ and Finland $(n=1)$ (Fig. 1).

\section{Phylogenetic tree}

The genetic tree view created as a result of the alignment of the sequences was shown in Figure 2. As a result, JQ710615 (Hap14) and JQ710605 (Hap23) were designated as two most distant isolates in two clusters owing to 11 nucleotide differences. Besides, JQ710615 caused the second furthest branching to JQ710620 (Hap09) due to 10 nucleotide differences. Basically, the isolates in the Hap28 group and the isolates in the Hap01 group formed two separate groups. Moreover, it was observed that the isolates in the Hap16 group were the closest to the Hap01 group.

\section{Discussion}

Taenia hydatigena is prevalent in herbivores in different regions of the globe. A slaughterhouse based study in Ethiopia estimated annual economic losses of US\$ 65.000 due to T. hydatigena infection in the livestock (Wondimu et al., 2011). In past few years, it has become prominant that further precedence should be given to $C$. tenuicollis therefore its veterinary and economic losses in the meat industry, particularly in undeveloped countries (Nourani et al., 2010; Samuel \& Zewde, 2010; Scala et al., 2015). Understanding the genetic identification of the parasite will be very important to control of like this parasitic infection. This is the first study about in silico analysis sheep isolates of $\mathrm{C}$. tenuicollis $\mathrm{mt}-\mathrm{CO} 1$ gene region.

The mt-CO1 gene is among the most popular mitochondrial DNA genes, used to study the phylogeny, specific strain variation, and historical biology of helminth parasites (Liu et al., 2012; Jia et al., 2012; Biswal et al., 2014; Liu et al., 2014). The mt-C01 gene of taeniid cestodes has been indicated to be a promising candidate for the classification of intra- and extra specific variants (Bowles et al., 1992). One of the major advantage is that mitochondrial DNA is present in more than one copy per cell, it has a high diagnostic value, especially when samples were broken. In addition, the mt-DNA has a high mutation rate and undergoes little or no recombination (i.e. mutations accumulate progressively) (Saarma et al., 2009). Therefore, in current study the mt-CO1 gene sequence was used to analyze the selected isolates for in-silico analysis.

Taenia hydatigena is one of the most ubiquitous taeniid species between sheep and dogs, and the parasite appears to be dispersed around the world for a long time through human migration and animal transport. Monitoring the vertical and horizontal spread of meta-analytical studies are important in terms of evaluating the effectiveness of protection and control measures. In this study, 
phylogenetic relationships between sheep isolates of $C$. tenuicollis $\mathrm{mt}-\mathrm{CO} 1$ gene isolated from different geographies were examined in-silico and the vertical spread of the highly conserved mt-CO1 gene sequences over the years was shown, on the other hand, horizontal spread has been revealed geographically.

Neutrality tests such as Tajima D, Fu's Fs were used to test the neutrality of values such as nucleotide variability and population expansion (Korneliussen et al., 2013). While Tajima D focuses on old mutations that can reflect population events for a long time, Fu's Fs value is mainly sensitive to the last mutation.

It has been determined that the main haplotype reported for the $\mathrm{mt}-\mathrm{CO} 1$ gene region of $\mathrm{C}$. tenuicollis is common. Indeed, the finding of in-silico analysis performed revealed that the sequences in only four countries such as Palestine ( $n=11)$, Iraq $(n=4)$, Iran $(n=4)$ and Italy $(n=3)$ were among the main haplotype of the sequences reported from seven countries. It shows that there was no genetic difference between the $C$. tenuicollis isolates detected in sheep in the Sardinia region of Italy, where an island with an isolated geographical location, and the isolates from Iran, Iraq and Palestine. Indeed it was remarkable that 3 of the 14 isolates examined in Sardinia were included in the main haplotype.

Total haplotype diversity and total nucleotide diversity were relatively low for Palestinian isolates having values of 0.705 and 0.0045 , respectively. These results shows that Palestinian C. tenuicollis haplotypes were not genetically different. In this case, it is not surprising that 11 out of 21 isolates that constitute the main haplotype belong to sheep isolates of Palestinian origin. With the feature of taeniid populations being hermaphrodite, self-fertilization can maintain intermediate gene flow, leading to inraspecific phenotype monotony (Boufana et al., 2015b; Nakao et al., 2003). This feature is consistent with the low haplotype variation observed in Palestine for T. hydatigena metacestodes derived from sheep. The genetic variation in the mt-CO1 gene observed in the Palestinian isolate was lower than the values reported among other countries, as seen in table 2 (Boufana et al., 2015a; Rostami et al., 2015). These results might be due to low prevalence and spread of $C$. tenuicollis, the smaller Palestine territory and current management system (Adwan et al., 2018).

The highest haplotype diversity in the current study was identified in Iranian sheep isolates, followed by Sardinian and Palestinian isolates. 35 haplotypes were identified in 40 Iranian isolates. The formation of unique (single) haplotypes (27 out of 38 ) in Iranian sheep isolates were an indicator of this situation. These findings probably indicate that sheep was first domesticated in the middle east countries and that $C$. tenuicollis first appeared in this geographically and then spread to Europe and other continents (Kinkar et al., 2018). It was quite interesting to identify the two furthest haplotypes from the same country (Iran: JQ710605 (Hap23)JQ710615 (Hap14)). Although, there were 6 years between the submission dates of Chinese isolates, it has been found that there was no haplotype difference between the Chinese isolates. Moreover, the low number of samples prevents us to make definitive comments on this issue. It might be possible that the Chinese isolates form a separate haplotype because of the four nucleotide difference between the isolates that make up the main haplotype. Finland isolates with accession number EU544551 (Hap46) also formed a separate haplotype due to the single nucleotide difference from the main haplotype. Indian isolate (DQ995656) was located in Hap16 (with Sardinia, $(n=3)$, Iran, $(n=2)$, Palestine, $(n=2)$ and India $(n=1)$ ), which is the second main haplotype with a single nucleotide difference from the main haplotype.

In conclusion, the highest haplotype diversity was detected in Iranian sheep and $88.6 \%$ of the haplotypes were geographically unique. Besides, 44 polymorphic sites were identified and large haplotype and weak nucleotide diversities were detected in mtC01 gene. There were $80.5 \%$ (38/47) unique single haplotype and this ratio was highest observed for $C$. tenuicollis from sheep originating from Iran isolates, followed by Sardinia, Palestine and Finland. If the current evolving conditions continue, genetic differences in $T$. hydatigena sheep isolates may be increased, and new strains and/or genotypes may be emerged. Finally, the complete mitochondrial genome sequence may be useful for understanding of the molecular ecology and population genetics of $T$. hydatigena.

\section{Acknowledgments}

This work was supported by a grant (1190014) from the Scientific and Technical Research Council of Turkey (TUBITAK).

\section{Conflict of interest}

The authors declare that there is no conflict of interests.

\section{References}

Adwan, K., Jayousi, A., Abuseir, S., Abbasi, I., Adwan, G., Jarrar, N. (2018): Genetic diversity of Taenia hydatigena in the northern part of the West Bank, Palestine as determined by mitochondrial DNA sequences. Acta Parasitol., 63(2): 299 - 303. DOI: 10.1515/ ap-2018-0034

Aydin, A. (2003): Hakkari Belediye mezbahasında kesilen hayvanlarda paraziter fauna tespit çalışmaları [Parasitic fauna detection studies in animals slaughtered in Hakkari Municipality Slaughterhouse] PhD Thesis, Turkey, Van: Yüzüncü Yıl University Institute of Health Science. (In Turkish)

Biswal, D.K., Chatterjee, A., Bhattacharya, A., Tandon, V. (2014): The mitochondrial genome of Paragonimus westermani (Kerbert, 1878), the Indian isolate of the lung fluke representative of the family Paragonimidae (Trematoda). Peer J., 2: 484. DOI: 10.7717/ peerj.484

Boufana, B., Scala, A., Lahmar, S., Pointing, S., Craig, P. S., Dessi, G., ZIDDA, A., PIPIA, A. P., VARCASIA, A. (2015a): A preliminary investigation into the genetic variation and population structure of 
Taenia hydatigena from Sardinia, Italy. Vet. Parasitol., 214(1-2): 67 - 74. DOI: 10.1016/j.vetpar.2015.08.003

Boufana, B., Lett, W., Lahmar, S., Griffiths, A., Jenkins, D., Buishi, I., Engliez, S., Alrefadi, M., Eljaki, A., Elmestirl, F. (2015b): Canine echinococcosis: genetic diversity of Echinococcus granulosus sensu stricto (ss) from definitive hosts. J. Helminthol., 89(6): 689 698. DOI: 10.1017/S0022149X15000395

Bowles, J., BLaIR, D., McManus, D.P. (1992): Genetic variants within the genus Echinococcus identified by mitochondrial DNA sequencing. Mol. Biochem. Parasitol., 54(2): 165 - 173. DOI: 10.1016/0166-6851(92)90109-W

Chembensofu, M., Mwape, K., Van Damme, I., Hobbs, E., Phirl, I., Masuku, M., Zulu, G., Colston, A., Willingham, A., Devleesschauwer, B. (2017): Re-visiting the detection of porcine cysticercosis based on full carcass dissections of naturally Taenia solium infected pigs. Parasit Vectors, 10(1): 572. DOI: 10.1016/j.vetpar.2008.02.002 DEGER, S., BICEK, K. (2005): Tatvan belediye mezbahasında kesilen koyun, keçi ve sığırlarda larval cestodiosis [Larval cestodiosis in sheep, goats and cattle slaughtered in Tatvan municipal slaughterhouse]. Van Vet. J., 16(1): $45-47$ (In Turkish)

Deger, S., Bicek, K., Gul, A., Eraslan, E. (2001): Van yöresinde koyun keçi ve sığırlarda, Cysticercus tenuicollis' in yaygınlığı [Prevalence of Cysticercus tenuicollis in sheep, goats and cattle in Van province of Turkey]. Van Health Sci J., 7(1-2): 95 - 97. (In Turkish) Harandi, M., MoazezI, S., Saba, M., Grimm, F., Kamyabi, H., SheiknzADEH, F., ShaRIFI, I., Deplazes, P. (2011): Sonographical and serological survey of human cystic echinococcosis and analysis of risk factors associated with seroconversion in rural communities of Kerman, Iran. Zoonoses Public Health, 58(8): 582 - 588. DOI: 10.1111/j.1863-2378.2011.01407.x

Jia, W., Yan, H., Lou, Z., NI, X., Dyachenko, V., LI, H., LitTlewood, D.T.J. (2012). Mitochondrial genes and genomes support a cryptic species of tapeworm within Taenia taeniaeformis. Acta Trop, 123(3): 154 - 163. DOI: 10.1016/j.actatropica.2012.04.006 Kara, M., GiciK, Y., SarI, B., Bulut, H., Arslan, M. (2009): A slaughterhouse study on prevalence of some helminths of cattle and sheep in Malatya Province, Turkey. J. Anim. Vet. Adv., 8(11): 2200 $-2205$

Kaufmann, J. (2013). Parasitic infections of domestic animals: a diagnostic manual. Birkhäuser.

Kinkar, L., Laurimäe, T., Balkaya, I., Casulli, A., Zait, H., Irshadullah, M., Sharbatkhorl, M., Mirhend, H., Rostami-Nejad, M., Ponce-GorDo, F. (2018): Genetic diversity and phylogeography of the elusive, but epidemiologically important Echinococcus granulosus sensu stricto genotype G3. Parasitology, 145(12): 1613 - 1622. DOI: 10.1017/S0031182018000549

Korneliussen, T.S., Moltke, I., Albrechtsen, A., Nielsen, R. (2013): Calculation of Tajima's $D$ and other neutrality test statistics from low depth next-generation sequencing data. BMC Bioinformatics, 14(1): $1-14$

Kumar, S., Stecher, G., LI, M., Knyaz, C., Tamura, K. (2018): MEGA $\mathrm{X}$ : molecular evolutionary genetics analysis across computing platforms. Mol Biol Evol, 35(6): 1547 - 1549. DOI: 10.1093/molbev/msy096

Leigh, J., Bryant, D., Steel, M. (2016): PopArt .Version 1.7

Mellau, L., Nonga, H., Karimuribo, E. (2010): A slaughterhouse survey of liver lesions in slaughtered cattle, sheep and goats at Arusha, Tanzania. Res. J. Vet. Sci., 3(3): $179-188$

LIU, G.H., LI, C., LI, J.Y., ZHou, DH., XIONG, R.C., LIN, R.Q., ZHU, $X . Q$. (2012): Characterization of the complete mitochondrial genome sequence of Spirometra erinaceieuropaei (Cestoda: Diphyllobothriidae) from China. Int J Biol Sci., 8(5): 640. DOI: 10.7150/ ijbs.4096

Liu, G.H., Yan, H.B., Otranto, D., Wang, X.Y., Zhao, G.H., Jia, W.Z., ZHU, X.Q. (2014): Dicrocoelium chinensis and Dicrocoelium dendriticum (Trematoda: Digenea) are distinct lancet fluke species based on mitochondrial and nuclear ribosomal DNA sequences. Mol Phylogenet Evol, 79, 325 - 331. DOI: 10.1016/j. ympev.2014.07.002

NaKaO, M., SAKO, Y., ITO, A. (2003): Isolation of polymorphic microsatellite loci from the tapeworm Echinococcus multilocularis. Infect. Genet. Evol., 3(3): 159 - 163. DOI: 10.1016/S15671348(03)00070-4

Nimbalkar, R., Shinde, S., Kamtikar, V., Muley, S. (2011): Study on Taenia hydatigena in the slaughtered sheep (Ovis bharal) and goats (Capra hircus) in Maharashtra, India. Glob. Vet., 6(4): 374 $-377$

Nourani, H., Pirali Kheirabad, K., Rajabi, H., Banitalebl, A. (2010): Research note an unusual migration of Taenia hydatigena larval in a lamb. Trop. Biomed., 27(3): 651 - 656

Rostami, S., Salavati, R., Beech, R., Babael, Z., Sharbatkhori, M., Baneshi, M., Hajiallo, E., Shad, H., Harandi, M. (2015): Molecular and morphological characterization of the tapeworm Taenia hydatigena (Pallas, 1766) in sheep from Iran. J. Helminthol., 89(2): 150 - 157. DOI: 10.1017/S0022149X13000667

Rozas, J., Ferrer-Mata, A., Sánchez-Delbarrio, J.C., Guirao-Rico, S., Librado, P., Ramos-Onsins, S.E., Sánchez-Gracia, A. (2017): DnaSP 6: DNA sequence polymorphism analysis of large data sets. Mol. Biol. Evol., 34(12): 3299 - 3302. DOI: 10.1093/molbev/ $\mathrm{msx} 248$

Saarma, U., Jogisalu, l., Moks, E., Varcasia, A., Lavikainen, A., OKsanen, A., Simsek, S., Andresiuk, V., Denegri, G., González, L. M. (2009): A novel phylogeny for the genus Echinococcus, based on nuclear data, challenges relationships based on mitochondrial evidence. Parasitology, 136(3): 317 - 328. DOI: 10.1017/ S0031182008005453

Samuel, W., Zewde, G.G. (2010): Prevalence, risk factors, and distribution of Cysticercus tenuicollis in visceral organs of slaughtered sheep and goats in central Ethiopia. Trop Anim Health Prod, 42(6): 1049 - 1051. DOI: 10.1007/s11250-010-9537-y

Saulawa, M., Magaul, A., Faleke, O., Mohammed, A., Kudi, A., MusaWa, A., Sada, A., Ugboma, A., Akawu, B., SidI, S. (2011): Prevalence of Cysticercus tenuicollis cysts in sheep slaughtered at Sokoto abattoir, Sokoto state, Nigeria. Sokoto J. Vet. Sci., 9(2): 24 - 27 
Scala, A., Pipia, A. P., Dore, F., Sanna, G., Tamponi, C., Marrosu, R., Bandino, E., Carmona, C., Boufana, B., Varcasia, A. (2015): Epidemiological updates and economic losses due to Taenia hydatigena in sheep from Sardinia, Italy. Parasitol. Res., 114(8): 3137 - 3143. DOI: 10.1007/s00436-015-4532-x.

Scala, A., Urral, G., Varcasia, A., Nicolussi, P., Mulas, M., Goddi, L., Pipia, A. P., Sanna, G., Genchi, M., Bandino, E. (2016): Acute visceral cysticercosis by Taenia hydatigena in lambs and treatment with praziquantel. J. Helminthol., 90(1): 113 - 116. DOI: 10.1017/ S0022149X14000601

Sissay, M.M., Uggla, A., Waller, P.J. (2008): Prevalence and seasonal incidence of larval and adult cestode infections of sheep and goats in eastern Ethiopia. Trop Anim Health Prod, 40(6): 387 394. DOI: 10.1007/s11250-007-9096-Z

Sultan, K., Desoukey, A., Elsiefy, M., Elbahy, N. (2010). An abattoir study on the prevalence of some gastrointestinal helminths of sheep in Gharbia Governorate, Egypt. Glob. Vet., 5(2): 84 - 87 TAYLOR, M., CoOP, R., Wall, R. (2007): Veterinary Parasitology. 3rd edn. Blackwell Publishing. UK.

UTUK, A. E., PISKIN, F. C. (2012): Molecular detection and characterization of goat isolate of Taenia hydatigena in Turkey. Sci World J, 2012: 962732. DOI: 10.1100/2012/962732

Varcasia, A., Tanda, B., Giobbe, M., Solinas, C., Pipia, A.P., Malgor, R., Carmona, C., Garippa, G., Scala, A. (2011): Cystic echinococcosis in Sardinia: farmers' knowledge and dog infection in sheep farms. Vet. Parasitol., 181(2-4): 335 - 340. DOI: 10.1016/j. vetpar.2011.05.006

Wondimu, A., Abera, D., Hailu, Y. (2011): A study on the prevalence, distribution and economic importance of Cysticercus tenuicollis in visceral organs of small ruminants slaughtered at an abattoir in Ethiopia. J. Vet. Med. Anim. Health., 3(5): 67 - 74 